\title{
FAKTOR-FAKTOR YANG BERHUBUNGAN DENGAN KEJADIAN BAYI BERAT LAHIR RENDAH DI RSU DAERAH KABUPATEN SUMEDANG PERIODE TAHUN 2016
}

\author{
Wulan Nur Insani, S.ST, M.Kes ${ }^{1)}$, Erni Saraswati, A.Md.Keb ${ }^{2)}$ \\ e-mail : wulannurinsani@yahoo.co.id
}

\section{A. Abstrak}

Bayi Berat Lahir Rendah (BBLR) termasuk faktor utama dalam peningkatan mortalitas, morbiditas, dan disabilitas neonatus, bayi, dan anak serta memberikan dampak jangka panjang terhadap kehidupannya di masa depan. Adapun faktor-faktor yang berhubungan dengan kejadian BBLR di RSU Daerah Kabupaten Sumedang, diantaranya usia ibu, tingkat pendidikan, anemia, PEB, dan kehamilan kembar. Faktor-faktor tersebut akan dianalisis dengan tujuan untuk mengetahui gambaran tiap-tiap variabel dan hubungan antara masing-masing variabel independen dengan variabel dependen.

Jenis penelitian ini menggunakan metode deskriptif analitik dengan pendekatan cross-sectional. Adapun data yang digunakan adalah data sekunder seluruh ibu bersalin dari rekam medis RSU Daerah Kabupaten Sumedang sejumlah 3.741 ibu dengan teknik pengambilan sampel simple random sampling dengan jumlah 362 sampel. Analisis data yang digunakan adalah analisis univariat dan analisis bivariat dengan menggunakan uji statistik Chi-Square.

Hasil penelitian menunjukkan faktor PEB dan kehamilan kembar memiliki hubungan yang signifikan terhadap kejadian BBLR dengan masing-masing nilai $p=0,001$ dan $p=$ 0,000 sehingga hipotesis diterima. Sedangkan faktor usia ibu, tingkat pendidikan ibu, dan anemia memperlihatkan hasil tidak ada hubungan yang signifikan terhadap kejadian BBLR dengan masing-masing nilai $p=0,45, p=0,100$, dan $p=0,573$ dengan keputusan hipotesis ditolak.

Simpulan dan saran dari penelitian ini adalah faktor-faktor yang berhubungan harus mendapat perhatian khusus dari tenaga kesehatan agar kejadian BBLR dapat diturunkan dan bagi faktor-faktor yang dinyatakan tidak berhubungan pada penelitian ini tetap perlu diwaspadai.

Kata Kunci $\quad$ : BBLR, usia ibu, tingkat pendidikan ibu, PEB 


\section{B. Pendahuluan}

Menurut World Health

Organization (WHO) tahun 2012 Angka Kematian Bayi (AKB), yaitu 42 per 1.000 kelahiran hidup (KH). Indonesia memiliki program berskala internasional yang dikenal dengan Millenium Development Goals (MDGs) atau disebut juga sasaran pembangunan Millenium tahun 2015. Terdapat enam point dalam MDGs yang ingin dicapai, satu diantaranya adalah poin keempat tentang mengurangi tingkat kematian anak. Dari pengalaman era MDGs (2000-2015), Indonesia ternyata belum berhasil menurunkan angka kematian ibu yang dapat berpengaruh juga terhadap angka kematian bayi. ${ }^{(1)}$

Hingga akhir tahun 2015, Indonesia berpeluang gagal mencapai sasaran-sasaran MDGs, kecuali angka kematian bayi. Target-target yang berpeluang gagal untuk dicapai itu diantaranya: (i) Penurunan angka kematian ibu, (ii) Penurunan angka kematian balita, (iii) Penurunan angka AIDS/HIV, (iv) Cakupan air minum dan sanitasi. (2)

SDGs (Sustainable Development Goals) tidak lain merupakan kelanjutan dari target-target MDGs dalam hal bagaimana mewujudkan pembangunan manusia. Keempat sasaran yang belum selesai itu tidak dapat dilupakan dan diabaikan begitu saja, karena sasaransasaran tersebut juga termuat kedalam beberapa Tujuan dan Sasaran SDGs. Oleh karena itu mulai tahun 2016 Tujuan Pembangunan Berkelanjutan (SDGs) 2015-2030 secara resmi menggantikan Tujuan Pembangunan Millenium (MDGs). Salah satu perubahan mendasar yang dibawa oleh SDGs adalah prinsip "tidak ada seorang pun yang ditinggalkan". SDGs juga mengandung prinsip yang menekankan kesetaraan antar-negara dan antarwarga negara. SDGs berlaku untuk semua (universal) negara-negara anggota PBB, baik negara maju, miskin, dan negara berkembang. ${ }^{(2)}$

Hasil Survei Penduduk Antar

Sensus (SUPAS) tahun 2015 menunjukkan Angka Kematian Bayi (AKB) sebesar 22,23 per 1000 kelahiran hidup. Berdasarkan program MDGs tahun 2015 untuk menurunkan AKB, maka angka tersebut telah mencapai target MDGs, yakni sebesar 23 per 1000 kelahiran hidup. ${ }^{(3)}$

AKB di Provinsi Jawa Barat tahun 2014 sebesar 3.937 kasus. Adapun angka kematian bayi per 1000 kelahiran hidup menurut kabupaten/kota di Provinsi Jawa Barat, Kabupaten Sumedang sebesar 9,68\% dengan peringkat ketiga tertinggi di Provinsi Jawa Barat. ${ }^{(4)}$

BBLR termasuk faktor utama dalam peningkatan mortalitas, morbiditas, dan disabilitas neonatus, bayi, dan anak serta memberikan dampak jangka panjang terhadap kehidupannya di masa depan. Adapun menurut data statistik, angka kesakitan dan kematian pada nenonatus di negara berkembang adalah tinggi, dengan penyebab utama adalah berkaitan dengan BBLR. ${ }^{(5)}$

Di negara berkembang, terdapat 20 juta kejadian bayi lahir BBLR dan lebih dari setengahnya terjadi di Asia Tenggara, termasuk Indonesia. Dalam satu tahun terjadi kematian bayi sebanyak 89.000 bayi meninggal disebabkan oleh BBLR. Secara statistik menunjukkan 90\% kejadian BBLR didapatkan di negara berkembang dan angka kematiannya 35 kali lebih tinggi dibanding pada bayi dengan berat badan lahir lebih dari 2.500 gram. $^{(5)}$

Menurut data dari Badan Pusat Statistik (BPS) Provinsi Jawa Barat menyebutkan bahwa tahun 2012 jumlah BBLR di Jawa Barat sebanyak 18.997 kejadian. Dapat dikatakan ada sekitar $10 \%$ balita Indonesia tahun 2015, terlahir dengan BBLR. ${ }^{(6)}$ 
Pada tahun 2016 di Kabupaten Sumedang, angka kejadian BBLR sebanyak 692 kasus. Sedangkan data yang bersumber dari RSU Daerah Kabupaten Sumedang menyatakan angka kelahiran bayi dengan BBLR sebesar 739 kejadian dari 5.454 kelahiran hidup. (7)

Berat badan merupakan salah satu indikator kesehatan pada bayi yang baru lahir. Secara dasar, bayi dengan berat badan lahir rendah (BBLR) dan bayi dengan berat badan berlebihan, yaitu lebih dari 3800 gram rentan mengalami masalah kesehatan. Tidak semua bayi dengan berat lahir kurang dari 2.500 gram lahir prematur. Demikian pula tidak semua bayi dengan berat lahir lebih dari 2.500 gram lahir secara aterm.

Kejadian BBLR dapat terjadi dan dapat dipengaruhi oleh beberapa faktor, seperti ibu yang mempunyai penyakit yang langsung berhubungan dengan kehamilan, dan usia ibu. ${ }^{(5)}$ Standar pelayanan kesehatan ibu hamil

dianjurkan untuk menjamin perlindungan terhadap ibu hamil dan atau janin berupa deteksi dini faktor risiko, pencegahan, dan penanganan dini komplikasi kehamilan. Penilaian terhadap pelaksanaan pelayanan kesehatan ibu hamil dapat dilakukan dengan melihat cakupan $\mathrm{K} 1$ dan K4. ${ }^{(3)}$

Berdasarkan uraian di atas, yang menarik perhatian untuk peneliti adalah faktor-faktor yang berhubungan dengan kejadian bayi BBLR di RSU Daerah Kabupaten Sumedang pada periode 1 Januari 2016 - 31 Desember 2016. Oleh karena itu peneliti bermaksud untuk menganalisis faktor-faktor tersebut dan berharap mampu mendeskripsikan hasil dari analisis pada akhir penelitian.

Bayi dengan Berat Badan Lahir Rendah (BBLR) adalah bayi baru lahir yang berat badan lahirnya kurang atau sama dengan 2500 gram. Hal ini didasarkan pada pengertian BBLR

menurut WHO (1961) yang menyatakan bahwa semua bayi yang baru lahir dengan berat lahir kurang atau sama dengan 2500 gram disebut Low Birth Weight infant (LBW). ${ }^{(8)}$

Berat badan lahir sangat penting diperhatikan karena berhubungan erat dengan kelangsungan hidup bayi selanjutnya. Bayi Berat Lahir Rendah akan meningkatkan morbiditas dan mortalitas bayi. ${ }^{(9)}$

Patofisiologi dari BBLR, yaitu asupan gizi yang kurang atau adanya komplikasi pada ibu hamil yang

kemudian secara otomatis menyebabkan kurangnya asupan gizi bagi janin. $^{(8)}$

Kejadian BBLR yang dibahas peneliti berhubungan dengan beberapa faktor. Faktor tersebut diantaranya faktor usia ibu, tingkat pendidikan ibu, dan pre-eklampsia berat (PEB).

\section{Metode}

Metode deskriptif analitik dengan pendekatan cross-sectional. Teknik pengumpulan sampel pada penelitian ini menggunakan teknik simple random sampling dengan jumlah sampel sebanyak 362 kejadian

persalinan, didapat dengan menggunakan rumus menurut Slovin.

Untuk mengetahui hubungan dari fakor usia ibu dengan kejadian BBLR, tingkat pendidikan ibu dengan kejadian BBLR, dan PEB dengan kejadian BBLR, maka dilakukan uji statistik. Uji yang digunakan adalah uji Chi-Square. 


\section{Hasil Penelitan}

Data hasil analisis univariat karakteristik variabel ini meliputi faktor usia, tingkat pendidikan, PEB, dan BBLR dari hasil pengkajian data adalah sebagai berikut:

Tabel 1

Distribusi Frekuensi Hasil Analisis Univariat Faktor-Faktor yang Berhubungan dengan Kejadian Bayi Berat Lahir Rendah di RSU Daerah Kabupaten Sumedang

\begin{tabular}{|c|c|c|}
\hline Karakteristik Variabel & $\begin{array}{c}\text { Frekuensi } \\
\text { (F) }\end{array}$ & $\begin{array}{c}\text { Persentase } \\
(\mathbf{\%})\end{array}$ \\
\hline Usia Ibu & & 31,2 \\
\hline - $<20$ atau $>35$ tahun & 113 & 68,8 \\
\hline - 20-35 tahun & 249 & 59,1 \\
\hline Pendidikan & & 40,9 \\
\hline - SD - SMP & 214 & 5,0 \\
\hline - SMA - PT & 148 & 95,0 \\
\hline PEB & & \\
\hline - PEB & 18 & 24,0 \\
\hline - Tidak PEB & 344 & 76,0 \\
\hline BBLR & & 87 \\
\hline - BBLR & 275 & \\
\hline - Tidak BBLR & & \\
\hline
\end{tabular}

Setelah dilakukan analisis statistik dengan uji Chi-Square maka dapat dilihat hasil uji statistiknya adalah sebagai berikut:

Tabel 2

Hubungan Usia Ibu terhadap Kejadian Bayi Berat Lahir Rendah di RSU Daerah Kabupaten Sumedang

\begin{tabular}{|c|c|c|c|c|c|c|c|}
\hline \multirow{3}{*}{ Usia } & \multicolumn{4}{|c|}{ BBLR } & \multirow{2}{*}{\multicolumn{2}{|c|}{ Total }} & \multirow{3}{*}{ p-value } \\
\hline & \multicolumn{2}{|c|}{ BBLR } & \multicolumn{2}{|c|}{ Tidak BBLR } & & & \\
\hline & $\mathbf{F}$ & $\%$ & \begin{tabular}{l|l}
$\mathbf{F}$ \\
\end{tabular} & $\%$ & $\mathbf{F}$ & $\%$ & \\
\hline $\begin{array}{l}\text { Berisiko } \\
(<20 \text { tahun atau }>35 \\
\text { tahun })\end{array}$ & 30 & 26,5 & 83 & 73,5 & 113 & 100 & \multirow[t]{2}{*}{0,534} \\
\hline $\begin{array}{l}\text { Tidak Berisiko } \\
\text { (20 tahun }-35 \text { tahun) }\end{array}$ & 57 & 22,9 & 192 & 77,1 & 249 & 100 & \\
\hline
\end{tabular}

Berdasarkan hasil pada tabel 4.2, disebutkan nilai $p$-value adalah $\mathrm{p}=0,534$. Nilai tersebut lebih besar dari $\alpha=0,05$.

Setelah dilakukan analisis statistik dengan uji Chi-Square maka dapat dilihat hasil uji statistiknya adalah sebagai berikut: 
Tabel 3 Hubungan Tingkat Pendidikan Ibu terhadap Kejadian Bayi Berat Lahir Rendah di RSU Daerah Kabupaten Sumedang

\begin{tabular}{|c|c|c|c|c|c|c|c|}
\hline \multirow{3}{*}{ Tingkat Pendidikan } & \multicolumn{4}{|c|}{ BBLR } & \multirow{2}{*}{\multicolumn{2}{|c|}{ Total }} & \multirow{3}{*}{ p-value } \\
\hline & \multicolumn{2}{|c|}{ BBLR } & \multicolumn{2}{|c|}{ Tidak BBLR } & & & \\
\hline & $\mathbf{F}$ & $\%$ & $\mathbf{F}$ & $\%$ & $\mathbf{F}$ & $\%$ & \\
\hline $\begin{array}{l}\text { Berisiko } \\
\text { (SD-SMP) }\end{array}$ & 58 & 27,1 & 156 & 72,9 & 214 & 100 & \multirow{2}{*}{0,106} \\
\hline $\begin{array}{l}\text { Tidak Berisiko } \\
\text { (SMA-PT) }\end{array}$ & 29 & 19,6 & 119 & 80,4 & 148 & 100 & \\
\hline
\end{tabular}

Berdasarkan hasil pada tabel 4.3, nilai $p$-value sebesar $p=0,106$. Nilai tersebut lebih besar dari $\alpha=0,05$.

Setelah dilakukan analisis statistik dengan uji Chi-Square maka dapat dilihat hasil uji statistiknya adalah sebagai berikut:

Tabel 4 Hubungan PEB terhadap Kejadian Bayi Berat Lahir Rendah di RSU Daerah Kabupaten Sumedang

\begin{tabular}{|c|c|c|c|c|c|c|c|}
\hline \multirow{3}{*}{ PEB } & \multicolumn{4}{|c|}{ BBLR } & \multirow{2}{*}{\multicolumn{2}{|c|}{ Total }} & \multirow{3}{*}{ p-value } \\
\hline & \multicolumn{2}{|c|}{ BBLR } & \multicolumn{2}{|c|}{ Tidak BBLR } & & & \\
\hline & $\mathbf{F}$ & $\%$ & $\mathbf{F}$ & $\%$ & $\mathbf{F}$ & $\%$ & \\
\hline Berisiko (PEB) & 11 & 61,1 & 7 & 38,9 & 18 & 100 & \\
\hline $\begin{array}{l}\text { dak Berisiko (Tidak } \\
\text { PEB) }\end{array}$ & 76 & 22,1 & 268 & 77,9 & 344 & 100 & 0,001 \\
\hline
\end{tabular}

Berdasarkan hasil pada tabel 4.5, $p$-value senilai $\mathrm{p}=0,001$. Nilai tersebut lebih kecil dari $\alpha=0,05$.

\section{E. Pembahasan}

$\mathbf{t}$

1. Gambaran Faktor Usia Ibu pada Persalinan di RSU Daerah Kabupaten Sumedang Tahun 2016 Analisis univariat yang telah dilakukan pada variabel usia ibu di RSU Daerah Kabupaten Sumedang mendapatkan jumlah ibu bersalin dengan usia $<20$ atau $>35$ tahun sebesar 113 orang $(31,2 \%)$ dan ibu dengan usia 20-35 tahun sebesar 249 orang $(68,8 \%)$. Usia reproduksi yang optimal bagi ibu adalah usia 20-35 tahun, usia dimana rahim ibu sudah siap menerima kehamilan, mental matang dan mampu merawat bayi dan dirinya sendiri. Sedangkan usia $<20$ tahun, rahim serta panggul ibu belum siap untuk menerima kehamilan karena belum tumbuh mencapai ukuran dewasa serta organ-organ reproduksi belum berfungsi secara sempurna. Begitupun usia $>35$ tahun sudah mengalami fase degeneratif sel-sel reproduksi. ${ }^{(10)}$

2. Gambaran Faktor Tingkat Pendidikan Ibu pada Persalinan di RSU Daerah Kabupaten Sumedang Tahun 2016

Analisis univariat pada tingkat pendidikan ibu di RSU Daerah Kabupaten Sumedang menunjukkan jumlah yang cukup tinggi yakni sebesar 214 orang $(59,1 \%)$ bagi tingkat pendidikan ibu yang rendah dan 148 orang $(40,9 \%)$ untuk tingkat pendidikan ibu yang tinggi. Tingkat pendidikan seringkali dihubungkan dengan tingkat 
sosial ekonomi dalam konteks kesehatan, dimana tingkat pendidikan yang rendah dapat membatasi seseorang untuk mendapatkan pekerjaan (AbuSaad dan Fraser, 2010). ${ }^{(11)}$

\section{Gambaran Faktor PEB pada Persalinan di RSU Daerah \\ Kabupaten Sumedang Tahun 2016}

Analisis univariat terhadap ibu bersalin RSU Daerah Kabupaten Sumedang dengan PEB sejumlah 18 orang $(5,0 \%)$ dan tanpa PEB 344 orang

$(95,0 \%)$. Pre-eklampsia berat bila tekanan darah mencapai atau lebih dari 160/110 mmHg. Meskipun tekanan darah belum mencapai 160/110 mmHg, pre-eklampsia termasuk kriteria berat apabila terdapat gejala lain, seperti proteinuria +3 pada tes celup stip, oliguria, sakit kepala hebat dan gangguan penglihatan, nyeri epigastrium atau ada ikterus, edema paru atau sianosis, trombositopenia, pertumbuhan janin yang terhambat. ${ }^{(12)}$ Sebisa mungkin preeklampsia berat harus dideteksi secara dini dengan cara periksa tekanan darah rutin ke tenaga kesehatan terutama saat kehamilan agar tidak terjadi komplikasi lainnya. Pre-

eklampsia merupakan gangguan kehamilan akut yang dapat terjadi saat ante, intra, bahkan postnatal. (13)

\section{Gambaran Kejadian BBLR pada Persalinan di RSU Daerah Kabupaten Sumedang Tahun 2016 Berdasarkanhasilanalisis} univariat, kejadian BBLR RSU Daerah Kabupaten Sumedang sebanyak 87 kasus $(24,0 \%)$ dan kejadian tidak BBLR sebesar 275 kasus (76,0\%). Semua bayi yang baru lahir dengan berat lahir kurang atau sama dengan 2500 gram

disebut Low Birth Weight infant (LBW). ${ }^{(8)}$
Analisis Bivariat

1. Hubungan Antara Faktor Usia Ibu dengan Kejadian BBLR di RSU Daerah Kabupaten Sumedang Tahun 2016

Analisis bivariat dengan uji statistik menggunakan Chi-Square terhadap usia ibu dengan kejadian BBLR menunjukkan nilai $\mathrm{p}=0,534$. Hal membuktikan bahwa hasil uji statistik lebih besar daripada $\alpha=0,05$ dengan asumsi tidak terdapat hubungan yang signifikan antara kedua variabel tersebut.

Usia ibu $<20$ tahun mempunyai potensi gawat obstetri karena usia tersebut tergolong usia remaja yang masih mengalami pertumbuhan dan perkembangan secara fisik dan psikologis. Usia ibu $>35$ tahun pun mempunyai potensi gawat obstetri karena pada usia tersebut organ

reproduksi mengalami penurunan fungsi. Kedua kriteria usia ibu tersebut dapat menimbulkan komplikasi, baik pada kehamilan, persalinan, maupun pasca persalinan. ${ }^{(4)}$

Penelitian ini sejalan dengan penelitian yang dilakukan Ulin Nuha (2016) yang menyatakan bahwa tidak ada hubungan yang signifikan antara usia ibu dengan kejadian BBLR ( $\mathrm{p}=$ $0,143)$. (14)

Usia ibu merupakan salah satu faktor tidak langsung terhadap kejadian BBLR. Namun kelahiran BBLR dapat dicegah jika saat masa kehamilan didampingi oleh pengelolaan kesehatan ibu dan janin dengan tepat terutama usia ibu dengan risiko tinggi ( $<20$ tahun atau $>35$ tahun).

Dalam hal ini, usia ibu tidak ada hubungan dengan kejadian BBLR berdasarkan uji statistik. Meskipun jumlah ibu bersalin dengan BBLR cukup banyak, ternyata usia saja tidak cukup untuk menerima hipotesis tersebut. 
2. Hubungan Antara Faktor Tingkat Pendidikan Ibu dengan Kejadian BBLR di RSU Daerah Kabupaten Sumedang Tahun 2016

Berdasarkan analisis bivariat dengan uji statistik Chi-Square, tingkat pendidikan rendah mendapat nilai $\mathrm{p}=$ 0,106 . Nilai tersebut menunjukkan bahwa hasil dari uji statistik lebih besar daripada $\alpha=0,05$ dengan asumsi tidak terdapat hubungan antara tingkat pendidikan dengan kejadian BBLR. Hasil penelitian ini sejalan dengan penelitian Puspitasari (2014) yang

menyimpulkan bahwa tingkat pendidikan ibu tidak memiliki hubungan dengan kejadian BBLR ( $\mathrm{p}=$ 0,098). . $^{(15)}$

Tingkat pendidikan seringkali dihubungkan dengan tingkat sosial, ekonomi, dan dalam konteks kesehatan, dimana tingkat pendidikan yang rendah dapat membatasi seseorang untuk mendapatkan layanan kesehatan. (11) Namun hasil yang diinginkan oleh peneliti tidak sesuai, dimana dapat dipengaruhi oleh faktor-faktor lain untuk membuktikan adanya hubungan.

Tingkat pendidikan dapat dikategorikan sebagai faktor tidak langsung penyebab BBLR. Namun tingkat pendidikan dapat diatasi dengan pemberian komunikasi, informasi, dan edukasi yang akurat serta pelayanan yang tepat tentang kesehatan pada ibu dan janin.

Di rumah sakit, kegiatan KIE yang tepat kepada pasien maupun bukan pasien dengan latar belakang pendidikan rendah agar hal-hal yang disampaikan dapat benar-benar dipahami oleh objek. Dengan demikian, pelayanan akan sesuai dengan kebutuhan dan tidak ada kesalahpahaman, terutama pada kasus dengan kegawatdaruratan.

Dokter, bidan, maupun perawat di rumah sakit berkewajiban untuk melakukan penyuluhan. Salah satunya dalam program kegiatan di poliklinik, yaitu penyuluhan. Hal ini bertujuan agar masyarakat awam paham tentang kesehatan.

\section{Hubungan Antara Faktor PEB dengan Kejadian BBLR di RSU Daerah Kabupaten Sumedang Tahun 2016}

Berdasarkan analisis bivariat terhadap faktor PEB dengan kejadian BBLR menunjukkan nilai $\mathrm{p}=0,001$. Nilai ini membuktikan bahwa melalui uji statistik faktor PEB pada ibu bersalin dengan kejadian BBLR di RSU Daerah Kabupaten Sumedang lebih besar dari $\alpha$ $=0,05$. Asumsi dari nilai tersebut adalah terdapat hubungan yang signifikan antara PEB dengan kejadian BBLR.

Hasil penelitian ini sejalan dengan penelitian dari Tintyarza (2013) yang menyebutkan bahwa pre-eklampsia mempunyai hubungan bermakna (signifikan) dengan kejadian BBLR. (16)

PEB merupakan salah satu faktor langsung terhadap kejadian BBLR. Hal ini dikarenakan PEB dapat menyebabkan pertumbuhan janin terhambat. PEB ditandai dengan tekanan darah tinggi atau biasa disebut hipertensi. (12) Hipertensi biasanya terjadi karena bertambahnya umur. Dinding arteri akan mengalami penebalan oleh adanya penumpukan zat kolagen pada lapisan otot, sehingga pembuluh darah akan berangsur-angsur menyempit dan menjadi kaku. Hal tersebut dapat memicu terhambatnya pasokan darah termasuk nutrisi dan oksigen ke janin berkurang dan mempengaruhi pertumbuhan janin. (17)

PEB masih dapat dikendalikan untuk mencegah terjadi kejang yang dapat dilakukan dengan pemantauan dan penanganan yang tepat sesuai advice dokter. Sama halnya dengan saat kehamilan, penanganan dalam persalinannya pun harus sesuai dan perlu dilakukan deteksi dini pada bayi baru lahir (neonatus). Hal tersebut dapat 
menjadi rujukan bagaimana keadaan ibu saat nifas dan menyusui serta kehidupan bayi selanjutnya.

\section{F. Simpulan dan Saran}

\section{Simpulan}

Berdasarkan hasil penelitian yang telah dilakukan terhadap faktor-fakto yang berhubungan dengan kejadian bayi berat lahir rendah di RSU Daerah Kabupaten Sumedang periode tahun 2016, dapat ditarik kesimpulan sebagai berikut:

a. Jumlah ibu bersalin dengan usia $<20$ tahun atau $>35$ tahun lebih sedikit dari pada ibu dengan usia 20-35 tahun.

b. Tingkat pendidikan rendah pada ibu bersalin menunjukkan jumlah yang cukup tinggi dibandingkan ibu bersalin dengan tingkat pendidikan tinggi.

c. Jumlah ibu bersalin dengan PEB lebih sedikit dibandingkan ibu bersalin tanpa PEB.

d. Angka kejadian BBLR lebih kecil dari pada kejadian tidak BBLR.

e. Faktor usia ibu dengan kejadian BBLR dikatakan tidak memiliki hubungan.

f. Faktor tingkat pendidikan ibu dengan kejadian BBLR tidak memiliki hubungan.

g. PEB dengan kejadian BBLR dinilai memiliki hubungan.

\section{Saran}

Dari faktor - faktor yang diteliti tidak ada yang berhubungan, sehingga perlu dikaji faktor lain yaitu anemia pada kehamilan sehingga untuk tenaga kesehatan khususnya bidan agar dapat lebih meningkatkan lagi penyuluhan pada faktor tersebut.

\section{G. Daftar Pustaka}

Vitrianingsih dkk. Faktor-faktor yang Berhubungan dengan Berat Lahir Bayi di RSUD Wonosari Gunungkidul Yogyakarta Tahun 2012. 2012. [Online] Tersedia:

http://journal.respati.ac.id/index.php/med ika/article/download/143/132 Diakses 20 Mei 2017

Hoelman, Mickael B. dkk. Panduan SDG's untuk Pemerintah Daerah (Kota dan Kabupaten) dan Pemangku Kepentingan Daerah. 2015.

[Online] Tersedia: infid.org/wpcontent/uploads/2015/11/Buku_PANDU AN-SDGs.pdf Diakses 20 Mei 2017 Depkes. 2015. Profil Kesehatan Indonesia. 2015. [Online] Tersedia: http://www.depkes.go.id/resources/down load/pusdatin/profil-kesehatanindonesia/profil-kesehatan-Indonesia2015.pdf Diakses 11 Mei 2017

Profil Kesehatan Provinsi Jawa Barat. 2014

Alya, Dian. Faktor-faktor yang Berhubungan dengan Bayi Berat Lahir Rendah (BBLR) di Rumah Sakit Ibu dan Anak Banda Aceh Tahun 2013. 2014. (Skripsi yang dipublikasi). STikes U'Budiyah Banda Aceh, Banda Aceh, Indonesia.

Profil Kesehatan Provinsi Jawa Barat. 2012

Dinas Kesehatan Kabupaten Sumedang. 2016

Amiruddin, Ridwan dan Hasmi.

Determinan Kesehatan Ibu dan Anak. Jakarta: CV Trans Info Media. 2014.

Nursaputri, Suharti. Analisis Faktor-faktor yang Berhubungan dengan Kejadian Bayi Berat Badan Rendah (BBLR) Pada Wanita Hipertiroid Kehamilan di Kabupaten Magelang Tahun 2014. 2015. [Online] Tersedia: http://lib.unnes.ac.id/20276/1/641141118 5-S.pdf Diakses 21 Mei 2017

Astuti, Sri dkk. 2017. Asuhan Ibu dalam Masa Kehamilan Buku Ajar Kebidanan-Antenatal Care (ANC). Jakarta: Penerbit Erlangga 
Septiani, Rini. Faktor Maternal pada Kejadian Berat Badan Lahir Rendah (BBLR) di Indonesia (Analisis Data RISKESDAS 2013). (Skripsi yang dipublikasi). Universitas Islam Negeri Syarif Hidayatullah, Jakarta, Indonesia. 2015

Dewi, Vivian Nanny Lia dan Tri Sunarsih. Asuhan Kehamilan untuk Kebidanan. Jakrta: Salemba Medika. 2012

Karima, Nurulia Muthi, dkk. Hubungan Faktor Risiko dengan Kejadian Pre-eklampsia Berat di RSUP dr. M Djamil Padang. 2013. [Online] Tersedia: http://jurnal.fk.unand.ac.id/index.php/artic le/download/299/281 Diakses 22 Juni 2017

Nurfitria, Ulin Nuha. Faktor-faktor yang Berkaitan dengan Kejadian Berat Bayi Lahir Rendah (BBLLR) di Wilayah Kerja Puskesmas Sukorejo Ponorogo. Bogor. 2016 [Online] Tersedia: repository.ipb.ac.id/jspui/bitstream/12345 666789/87044/1/I/16unn.pdf Diakses 25 Agustus 2017

Puspitasari, Rani. Hubungan Tingkat Pendidikan dan Pekerjaan Ibu dengan Kejadian Bayi Berat Lahir Rendah di RSU PKU Muhammadiyah Bantul. Yogyakarta. 2014. [Online] Tersedia:

opac.unisayogya.ac.id/1188/1/NASKAH \%20PUBLIKASI.pdf Diakses 25 Agustus 2017

Tintyarza, Adhitya Gilang. Hubungan Preeklampsi/Eklampsi dengan Kejadian Berat Badan Lahir Rendah pada Bayi di RSUD R.A. Kartini Jepara. Jepara. 2013. [Online] Tersedia: eprints.usm.ac.id/23944/13/Naskah_Publi kasi.pdf Diakses 25 Agustus 2017

V, Kumar dkk. Hypertensive Vascular Disease. Dalam: Robn dan Cotran Pathologic Basic of Disease, 7th edition. Philadelpia: Elsevier Saunders. 2005.p 528-529 [Online] Tersedia: juke.kedokteran.unila.ac.id Diakses 22 Agustus 